\title{
Spreadsheet simulation-based optimization for personnel capacity requirement in breakdown maintenance
}

\author{
Tan Hauw Sen ${ }^{1, *}$, Wan Hasrulnizzam Wan Mahmood ${ }^{1}$, and Siti Shahara Dolah ${ }^{1}$ \\ ${ }^{1}$ Dept. of Manufacturing Engineering Technology, Faculty of Engineering Technology, Universiti \\ Teknikal Malaysia Melaka, Hang Tuah Jaya, 76100 Durian Tunggal, Melaka, Malaysia
}

\begin{abstract}
This study's objective is to find out the optimum number of personnel in breakdown maintenance activities. Spreadsheet simulation was used for that purpose considered spreadsheet is relatively not an expensive simulation software, familiar to many people, easy to use, yet powerful enough to do the simulation. Input data included in the simulation are time to repair and time between failures which are generated randomly following normal and uniform distribution respectively. The distribution identified by using the histogram and chi-squared test for distribution to find the best-fit distribution. The simulation results show that, the optimum number of personnel obtained when utilization of maintenance personnel is maximized while the number and/or time machines/equipment waiting in queued for maintenance personnel was minimized. In that condition, the cost of breakdown maintenance will be optimum.
\end{abstract}

\section{Introduction}

The maintenance function plays an important role in a manufacturing system. The highperformance manufacturing system is achieved not from its operational design only, but also from the capability to maintain the condition of the system [1]. This refers to maintenance function that includes all actions to keep machines/equipment in the operating condition and daily problem solving to bring them back in operating condition after breakdown $[2,3]$.

Although maintenance function is important to support manufacturing system, it is often considered as a cost centre rather than a competitive advantage [4]. Commonly, the annual cost of maintenance runs between $7-15 \%$ of the investment [3]. U.S industry spent over $\$ 300$ billion per year for maintenance cost [2]. Chelson et al. [5] discovered that in manufacturing, maintenance cost could consume 2-10\% of the company's revenue. Most of the cost is breakdown maintenance cost due to production stop, productivity loss, miss delivery schedule, etc. Breakdown maintenance can cost $50 \%$ to $200 \%$ more than the

\footnotetext{
* Corresponding author: tanhauwsr@utem.edu.my
} 
preventive maintenance cost [6]. Therefore, optimum maintenance is achieved when all actions were taken at a minimum cost [7].

The ultimate goal of breakdown maintenance is to make the machine/equipment running again immediately. Ensuring resources, especially maintenance personnel, available when breakdown happened is critical to minimize breakdown maintenance cost. For that reason, Nyman and Levitt [8] suggested a division of work in the maintenance function with one of the group focus to urgent or emergency job which is breakdown maintenance.

It is not easy to determine an exact number of personnel required since the occurrences of breakdown are uncertain and random. Stochastic simulation is the most suitable tool to analyse system with uncertainty in the form of random variables with specific probability distributions $[9,10]$. Atlason et al. used Analytic Center Cutting Plane Method (ACCPM) simulation to optimize call centre staffing [11]. Mjema used SIMPLE++ simulation from AESOP GmbH to analyse personnel capacity requirement in the maintenance department [12]. However, simulation can be difficult, complicated, time-consuming and expensive because it requires special knowledge, skill, training and software. Therefore, spreadsheet simulation could be alternative for simulation analysis. Spreadsheet simulation is relatively simple, familiar by many people and relatively low cost. Although Spreadsheet is simple, it provides an almost complete set of tools for simulation [13]. Microsoft Excel is used throughout this study.

The main objective of this study was to find an optimum number of breakdown maintenance personnel that will maximize utilization of manpower and minimize cost caused by production loss due to production stoppage. The specific objectives of this study were to identify the probability distribution of time between failures (TBF) and time to repair (TTR) as the input of simulation in order to find out the optimum number of breakdown maintenance personnel required.

\section{Research methodology}

Operationally, breakdown maintenance activity is triggered by an event, which is a failure. The nature of this failure is random following a certain probability distribution. Fig. 1. show, when the failure occurs, and there are any available personnel, the breakdown maintenance activity can start immediately. But, if all the personnel busy, the machine/equipment will queue for repaired.

Fig. 2. show, when a repair is completed, the personnel state will change. If there is no machine/equipment waiting to be repaired, personnel status changes to idle; if there is one or more machines/equipment waiting, the personnel will start repairing the next machine/equipment.

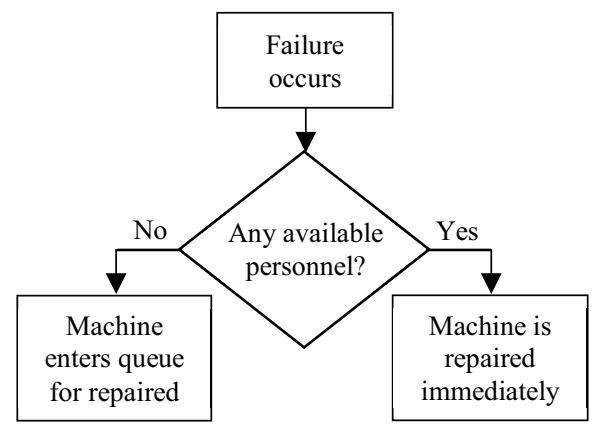

Fig. 1. Failure event flow diagram 


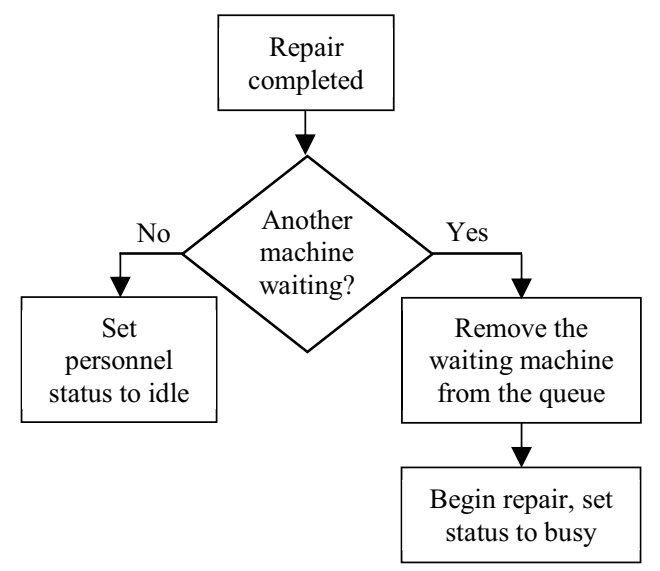

Fig. 2. Personnel state flow diagram

The real-life system used for the study was a Plastic Injection Moulding Department of a manufacturing company. The company belongs to the so-called a fully integrated contract manufacturing service provider of IT-related electronics and mechanical assemblies. The Department had 29 injection moulding machines with different tonnage that operate 3 shifts, 24 hours a day and 7 days a week. During the study, there were six breakdown maintenance personnel per shift who will respond if there was a failure.

TTR and TBF data used as input for simulation to optimize the number breakdown maintenance personnel required for the department. TTR is elapsed time needed to perform a maintenance activity that consists of repairing and replacing. TTR is random, can be a short-time period or long-time period, following certain probability distribution. TBF is a time between the first failure occurred, continued by a maintenance call to the next failure or next maintenance call. In another word, TBF is failure interarrival time. This TBF is also random following certain probability distribution.

The histogram was constructed from TTR and TBF data collected as shown in Fig. 3 and Fig. 4. Based on the figures, hypothesized distribution for TTR was a normal distribution and hypothesized distribution for TBF was a uniform distribution.

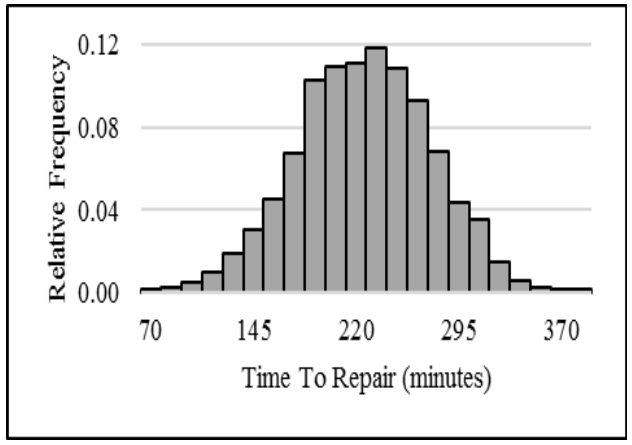

Fig. 3. Histogram of time to repair 


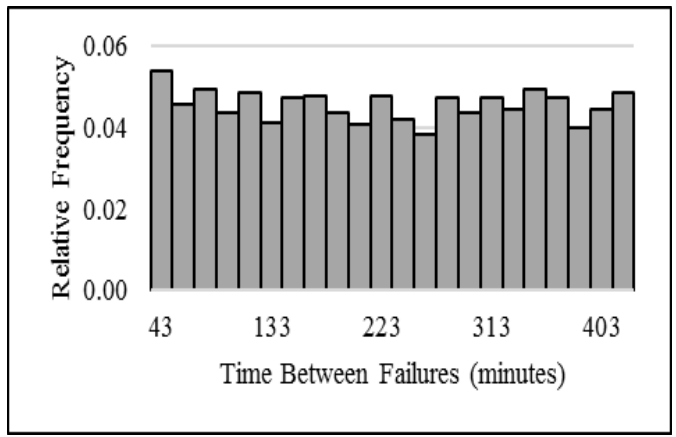

Fig. 4. Histogram of time between failures

The chi-square test for distribution was performed for both data, TTR data and TBF data, for fitting with hypothesized distribution under 0.05 significance level. Table 1 shown the results for TTR \& TBF data. As P-value for TTR and TBR were more than the significance level, hypothesized distribution was accepted for both data or in another word TTR data fit normal distribution and TBR data fit to uniform distribution.

Table 1. Chi-square test for distribution of TTR \& TBF data with significance level $=0.05$

\begin{tabular}{|l|c|r|}
\hline TTR & & TBF \\
\hline 0.000857 & Square Error & 0.000308 \\
\hline 14 & Degree of Freedom & 21 \\
\hline 15.9 & Test Statistic & 9.35 \\
\hline 0.332 & Corresponding P-value & 0.771 \\
\hline Accept & Decision & Accept \\
\hline
\end{tabular}

\section{Results and discussions}

The simulation results in this study are focused on three main performance measures, which are:

1. Maximum number of maintenance personnel "busy"

2. Utilization of maintenance personnel

3. Number and time machines/equipment waiting in queued for maintenance personnel

The breakdown maintenance system simulation used TTR and TBF as random input data produced random results. To interpret results accurately, the simulation should be run in several replications and results will be accumulated to get statistical performance results. Twelve replications represent a year of 43200-minutes (1 month) simulation were performed in this study. Three simulation scenarios were performed to find the optimum number of breakdown maintenance personnel.

The first simulation performed for the current condition with six personnel for breakdown maintenance. The maximum number of personnel "busy" during the simulation time shown in Fig. 5 and utilization of maintenance personnel shown in Fig. 6.

The maximum number of personnel "busy" at the same time is five personnel and only happened 1 time. Four personnel "busy" at the same time happened 5 times, three personnel "busy" at the same time happened 32 times, two personnel "busy" at the same time happened 85 times and one personnel "busy" happened 89 times. This brought the utilization of the personnel become low with average $18.09 \%$. With six breakdown 
maintenance personnel available, no machine/equipment found waiting for personnel in the queue to be repaired. In summary, it can be said six breakdown maintenance personnel is more than required that may increase the cost of breakdown maintenance in labour cost. From the results, it could be hypothesized only three or two personnel required.

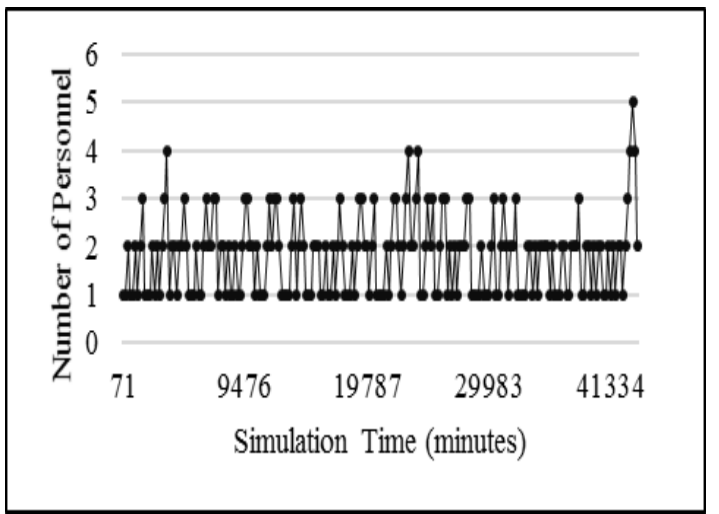

Fig. 5. Number of personnel "busy" over time in 6-personnel scenario simulation

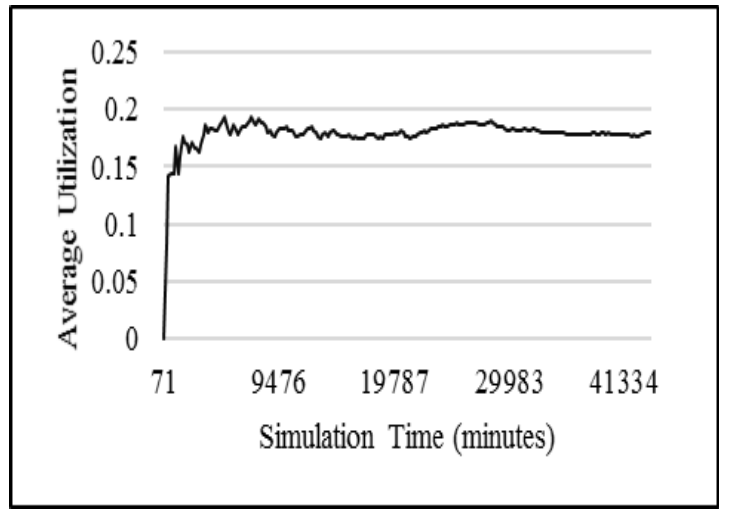

Fig. 6. Personnel utilization over time in 6-personnel scenario simulation

The second simulation carried out for optimization with 3 personnel for breakdown maintenance. The maximum number of personnel "busy" during simulation time shown in Fig. 7 and utilization of maintenance personnel shown in Fig. 8.

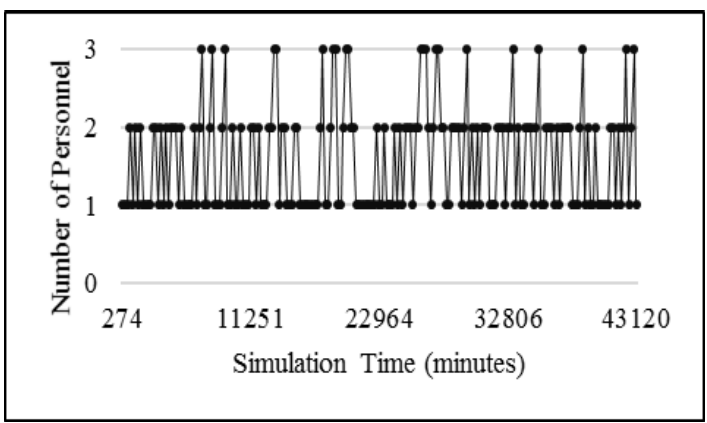

Fig. 7. Number of personnel "busy" over time in 3-personnel scenario simulation 


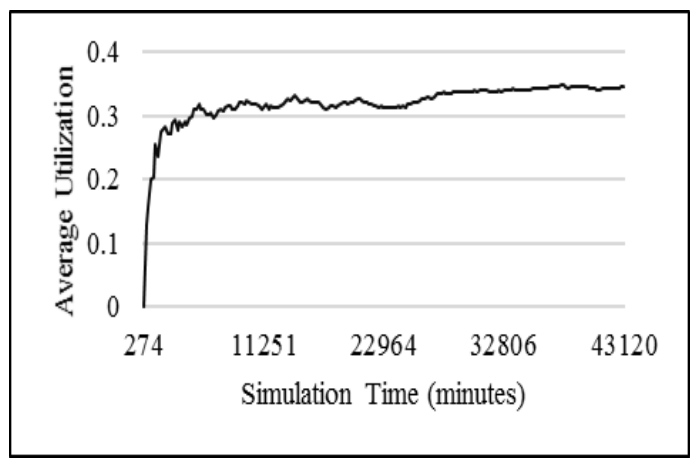

Fig. 8. Personnel utilization over time in 3-personnel scenario simulation

In the 3-personnel scenario, found that three or all of the personnel "busy" at the same time happened 21 times, two personnel "busy" at the same time happened 80 times and 1 personnel "busy" 100 times. The utilization of the personnel increases to $34.60 \%$ in average. The good news was still not found machine waiting for personnel in the queue to be repaired. With three personnel, the labour cost will be less compared to six personnel in breakdown maintenance.

The third simulation carried out for optimization with 2 personnel for breakdown maintenance. The maximum number of personnel "busy" during simulation time shown in Fig. 9 and average utilization of maintenance personnel shown in Fig. 10.

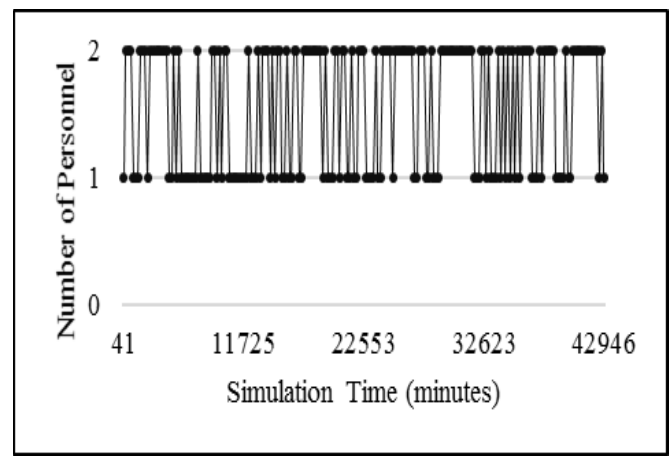

Fig. 9. Number of personnel "busy" over time in 2-personnel scenario simulation

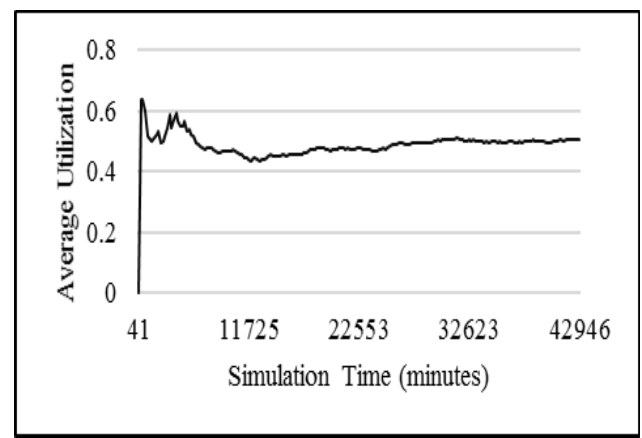

Fig. 10. Personnel utilization over time in 2-personnel scenario simulation 
In the 2-personnel scenario, found that two or all of the personnel "busy" at the same time happened 112 times and 1 personnel "busy" 89 times. Now, the utilization of the personnel increase to $50.61 \%$ on average, which means that it was likely there will be always while one technician was repaired, the other personnel available and stand by for next maintenance call-in. But, this resulting machine/equipment waiting for personnel in the queue to be repaired.

There were 31 occurrences where machine/equipment waiting for personnel in the queue to be repaired with averages waiting time 184.58 minutes. There was one occurrence that machine/equipment must wait for 515 minutes for personnel to repair the problem. Therefore, although the labour cost will decrease in the 2-personnel scenario compares to the 3-personnel scenario, the company need to calculate the cost due to production loss and miss scheduled caused by machine/equipment stopped waiting for repaired carefully. Considered number of machines/equipment and the waiting time, it seemed 2-personnel scenario was not preferred.Performance measures results for each simulation presented in Table 2 .

Table 2. The 43200-minutes simulation results for breakdown maintenance system

\begin{tabular}{|l|c|c|c|}
\hline \multicolumn{1}{|c|}{ Performance Measure } & $\begin{array}{c}\text { 6-Personnel } \\
\text { Simulation }\end{array}$ & $\begin{array}{c}\text { 3-Personnel } \\
\text { Simulation }\end{array}$ & $\begin{array}{c}\text { 2-Personnel } \\
\text { Simulation }\end{array}$ \\
\hline Number of failures & 212 & 201 & 201 \\
\hline Average TBF (minutes) & 202.66 & 214.53 & 213.66 \\
\hline Average TTF (minutes) & 219.97 & 222.66 & 216.27 \\
\hline Personnel Utilization & 0.1809 & 0.3460 & 0.5061 \\
\hline Max number personnel "busy" & 5 of 6 & 3 of 3 & 2 of 2 \\
\hline Number of machines queue & 0 & 0 & 31 \\
\hline Average waiting time in queue (minutes) & 0 & 0 & 184.58 \\
\hline Max waiting time in queue (minutes) & 0 & 0 & 515 \\
\hline
\end{tabular}

\section{Conclusions}

The main finding from the simulation results is the TTR and TBF are the dominant factors to the number of breakdown maintenance personnel required. Higher TTR will result to more personnel required while higher $\mathrm{TBF}$ will result to less personnel required. The efforts to reduce the workforce level in breakdown maintenance should be focused on how to reduce TTR and how to increase TBF. TTR could be reduced by improving the skill of the personnel. TBF could be reduced by improving preventive maintenance and maintenance engineering.

Maintenance cost directly correlated with the number of personnel available for breakdown maintenance. To reduce the cost of labour in breakdown maintenance, the company could reduce the number of personnel. However, the company should analyse the effects carefully since if it is done recklessly, it will cause machine/equipment stop operating waiting for personnel to be repaired. That situation can lead to bigger cost such as production loss and miss scheduled delivery. This spreadsheet simulation is a good tool for that kind of analysis.

This result is only valid when material and tools required for breakdown activity are always available. In addition, the skill of the personnel also assumed same. Further study could include those variables in the simulation to get more accurate results for decision making. 


\section{References}

1. W.R. Blischke, D.P. Murthy in: Introduction and Overview, Case Studies in Reliability and Maintenance, (John Wiley \& Son, USA, 2003)

2. B.S. Dhilon: Engineering Maintenance: A Modern Approach, (CRC Press, Florida, 2002)

3. R.K. Mobley in: Introduction to the Theory and Practice of Maintenance, Maintenance Engineering Handbook, $7^{\text {th }}$ ed, (McGraw-Hill, USA, 2008)

4. A. Salonen, M. Deleryd in: Cost of Poor Maintenance, JQME, 17(1), 63 (2011)

5. A.E. Haroun, S.O. Duffuaa in: Maintenance Organization, Handbook of Maintenance Management and Engineering, edited Ben-Daya et. Al., (Springer, London, 2009)

6. J.D. Campbell, A.K. Jardine: Maintenance Excellence: Optimizing Equipment LifeCycle Decisions, (CRC Press, Florida, 2001)

7. A. Kelly: Managing Maintenance Resources, (Butterworth-Heinemann, UK, 2006)

8. D. Nyman, J. Levitt: Maintenance Planning, Coordination and Scheduling, (Industrial Press, New York, 2010)

9. J. Banks, J.S. Carson II, B.L. Nelson, D.M. Nikol: Discrete-Event System Simulation, $5^{\text {th }}$ ed, (McGraw-Hill, USA, 2010)

10. H.K. Al Fares, S.O. Duffuaa in: Maintenance Forecasting and Capacity Planning, Handbook of Maintenance Management and Engineering, edited Ben-Daya et. Al., (Springer, London, 2009)

11. J. Atlason, M.A. Epelman, S.G. Henderson, Management Science, 54(2), 295 (2007)

12. E.A.M. JQME, 8(3), 253 (2002)

13. J.P. Pecherska, Y. Merkuryev, Proceedings $19^{\text {th }}$ European Conference on Modelling and Simulation, (2005) 